\title{
Volleyball injuries presenting in casualty: a prospective study
}

\author{
Lars Solgård, Allan Buhl Nielsen, Bjarne Møller-Madsen, Bent Wulff Jacobsen, \\ Johannes Yde and Jørn Jensen \\ Accident Analysis Centre, Orthopaedic Department, University Hospital, 8000 Århus C, Denmark
}

\begin{abstract}
During 1986, all sports injuries $(n=5222)$ were prospectively recorded at the two casualty departments in Arhus, Denmark. Volleyball injuries $(n=278)$ accounted for $5.3 \%$ of all injuries and were the fourth most common source of sports injuries. An evaluation of the rehabilitation period and the consequences of the injuries was undertaken by questionnaire three years after the injury. The injury incidence was 1.9 injuries/1000 inhabitants/year. Hand, finger, and ankle sprains were the most frequent injuries. Female players had significantly more hand/finger injuries than male players, who incurred more ankle/foot injuries. Knee $(6 \%)$ and ankle injuries $(31 \%)$ were responsible for the longest duration of absence from sports participation. There were relatively few chronic injuries. The study suggests the need to enhance prophylactic measures with regard to blocking and overhand pass techniques, in order to reduce the number and extent of ankle and hand/finger injuries.
\end{abstract}

(Br J Sports Med 1995; 29 : 200-204)

Keywords : volleyball injuries; prospective casualty report; epidemiology; traumatology

In Denmark, volleyball is played at a comparatively low competitive level. Nevertheless, it is very popular, and the Danish Volleyball Association had 19813 active members in 1989.

The players' position is either at the net, and during repetitive attack the players jump to play or spike the ball, often with extended fingers, or they are in a defence position, blocking at the net, or receiving the ball in a standing position with the forearms extented.

Volleyball is the only so called non-contact ball game played in teams, and a different pattern of injuries could be expected compared to the injuries in contact ball games. This has been analysed in several studies. ${ }^{1-3}$ Previous studies have shown a lower injury incidence in volleyball (2.8 and 3.1 injuries/1000 playing hours ${ }^{45}$ ) compared to soccer and handball (4.1 and 8.3 injuries/1000 playing hours ${ }^{2}$ ).

Both Yde and Nielsen and Schmidt-Olsen and Jørgensen found that most injuries occurred at the net, ${ }^{45}$ but Yde and Nielsen showed that many injuries also occurred in the defence position at the floor while diving. ${ }^{4}$ A study by Schafle et al was based on a

Correspondence to: Dr Lars Solgård, Mosekrogen 43, 2860 Søborg, Denmark population composed of experienced players, and this might be the possible explanation for the fact that only one out of over 1500 players suffered a chin laceration caused by a poorly executed dive. ${ }^{6}$

Schafle et al also found a relative absence of prophylactic taping of ankles and they were uncertain as to whether this might affect the rate of ankle sprains in volleyball, while Greene and Hillmann ${ }^{7}$ showed that orthosis prophylaxis provides useful initial, as well as reinjury, ankle protection.

The previously mentioned reports included less than 70 injured volleyball players. In this investigation, based on a higher number of injured athletes $(n=269)$, we expected to find a large number of volleyball injuries. The aim of this study was to make a thorough description of the epidemiology and traumatology of acute injuries occurring in Danish volleyball players and to evaluatate the consequences of the injuries.

\section{Methods}

During 1986, all sports injuries $(n=5222)$ were prospectively recorded at two casualty departments in Århus, Denmark.

In order to analyse the athletic condition of the injured volleyball players and the events related to the injuries, the patients were interviewed at the casualty departments by the physician in charge about their level of participation, weekly hours of sport, and the mechanism of injury. The region and type of the lesion and medical attention was recorded.

A sport injury was defined as an incident occurring during athletic activities at a sports area, causing the athlete to consult the casualty wards within $24 \mathrm{~h}$ of the accident. Table 1 gives details of the population; it can be seen that $3.3 \%(4728 / 142704)$ incurred a sports injury that year.

The consequences of the injuries were evaluated three years after injury. A questionnaire answered by 213 individuals $(79 \%)$ included the following information: level of participation at the time of injury, duration of absence from sport caused by the injury, time needed to reach previous level of activity, postinjury attention by player or coach, evaluation of rehabilitation and treatment, level of activity after returning to competition, absence from work, and 
Volleyball injuries: L Solgäd et al.

Table 1. Population data: age and sex, Århus, 1986

\begin{tabular}{|c|c|c|c|c|c|c|c|c|}
\hline & \multicolumn{2}{|c|}{$11-17$ years } & \multicolumn{2}{|c|}{$18-24$ years } & \multicolumn{2}{|c|}{$25-45$ years } & \multicolumn{2}{|c|}{ Total } \\
\hline & $M$ & $F$ & $M$ & $F$ & $M$ & $F$ & $M$ & $F$ \\
\hline $\begin{array}{l}\text { Inhabitants in } \\
\text { Arhus county }\end{array}$ & \multicolumn{2}{|c|}{23170} & \multicolumn{2}{|c|}{35158} & \multicolumn{2}{|c|}{84376} & \multicolumn{2}{|c|}{142704} \\
\hline $\begin{array}{l}\text { Active volleyball } \\
\text { club players in } \\
\text { Arhus county }\end{array}$ & 94 & 96 & 370 & 432 & 317 & 238 & 781 & 766 \\
\hline $\begin{array}{l}\text { Total number of sports } \\
\text { injuries }\end{array}$ & \multicolumn{2}{|c|}{1594} & \multicolumn{2}{|c|}{1624} & \multicolumn{2}{|c|}{1510} & \multicolumn{2}{|c|}{4728} \\
\hline
\end{tabular}

Note: Patients younger than 11 years of age and above 45 years of age are excluded in this table. This explains the difference in number of total sports injuries between the text and this table.

economic difficulties caused by the injury. The results were statistically analysed, and comparisons made with Fisher's exact test.

Injury rates were calculated as: volleyball player injuries/1000 hours of practice and games. Calculation of an injury risk was not possible, as we had no information on the number of exposure hours among the non-injured volleyball players in Århus. We calculated injury incidence as injuries/1000 inhabitants/year, and as injuries/1000 club players/year.

\section{Results}

Volleyball accounted for $5.3 \%$ of all injuries associated with sport and 269 players incurred 278 injuries. One hundred and seventeen were males ( $43 \%$ ). The average age was 23 years. Calculated from the total number of injured athletes $(n=5222)$ volleyball came fourth in the list of sports most likely to cause injuries.

Compared to the other sports (handball, soccer, basketball, badminton, and so on) volleyball players had a higher frequency of injuries to the hands or fingers $(45 \% / 25 \%)$ and ankle $(31 \% / 20 \%)$, but fewer injuries located in the other anatomical regions.

In the general population the injury incidence was 1.9, and in club players 89.9. The injury rate was 6.5 injuries/1000 hours of practice and games. Fifty two percent of the injured players were club players, $33 \%$ were injured in schools, and $16 \%$ during leisure time.

Nine percent of the active volleyball club players in Arhus (139/1547) were registered as injured in one year.

Sprains of the hand/fingers and ankle were most frequent (Figure). Injuries of the back included one fracture. There were two specific shoulder injuries. The knee injuries $(n=17)$ included two patello-femoral dislocations, one tear of the anterior cruciate ligament, one combined lesion (anterior cruciate + medial collateral), and one chronic overwork injury.

It was highly significant $(P<<0.001)$ that school/ educational players had more hand and finger injuries $(62 / 92)$ than club players $(45 / 142)$. Club players had significantly $(P<<0.001)$ more ankle injuries $(56 / 142)$ than school/educational players (16/92).

Ankle injuries occurred in players who were active (56\% $>5$ hours/week), while most players with

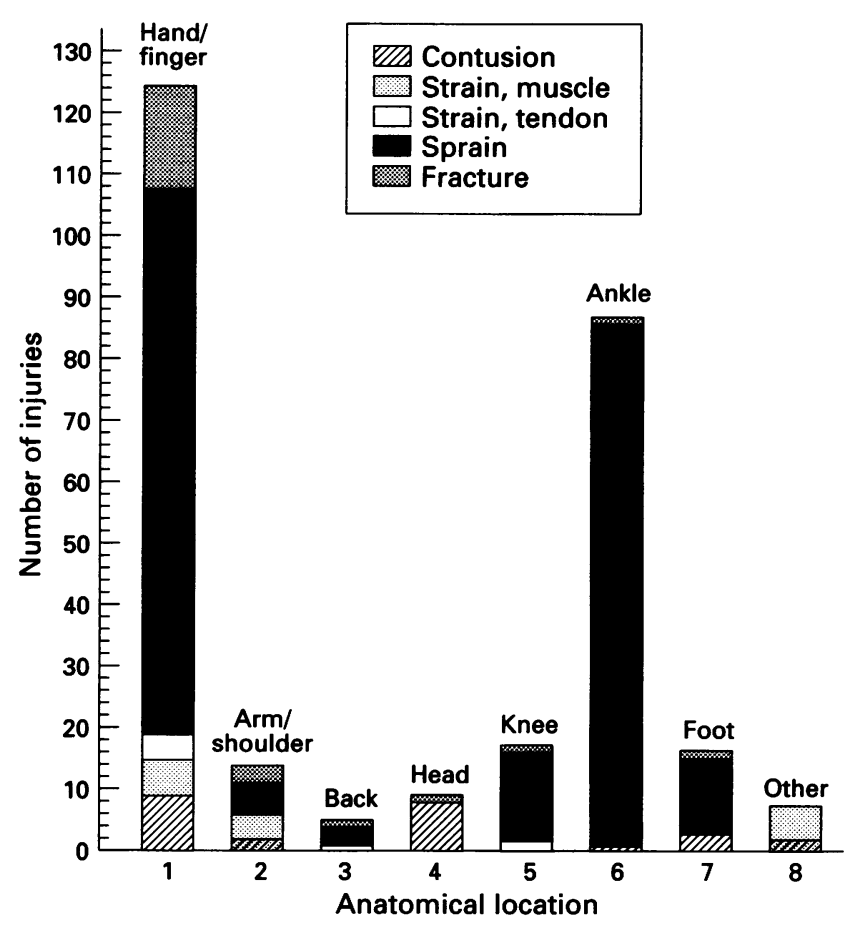

Volleyball injuries: patho-anatomical details of the study sample $(n=278)$.

shoulder/arm, knee and hand injuries had a low weekly activity $(71-85 \%<4$ hours/week).

Females (especially young female players) had more hand and finger injuries $(n=89)$ than males $(n=35)$ $(P<<0.001)$. Ankle and foot injuries were more common in males $(n=60)$ than in females $(n=42)$ $(P<<0.001)$. Knee injuries were more common among males (Table 2).

The relation between the level of volleyball playing and the injury pattern is shown in Table 3. More ankle and foot injuries and fewer hand and finger injuries occurred at elite or division level compared to the other levels, but the differencies were not significant.

\section{Traumatology}

Forty eight percent of the injuries were contact injuries. Most of the knee injuries (82\%) and the ankle/foot 
Table 2. Type of injury, related to age and sex

\begin{tabular}{|c|c|c|c|c|c|c|c|}
\hline \multirow[b]{2}{*}{ Location } & \multicolumn{2}{|c|}{$11-17$ years } & \multicolumn{2}{|c|}{$18-24$ years } & \multicolumn{2}{|c|}{$25-45$ years } & \multirow[b]{2}{*}{ Total } \\
\hline & $M$ & $F$ & $M$ & $F$ & $M$ & $F$ & \\
\hline Arm/shoulder & 1 & 3 & 4 & 4 & & 2 & 14 \\
\hline Hands/fingers & 6 & 41 & 13 & 22 & 16 & 26 & 124 \\
\hline Knee & & & 6 & 2 & 5 & 4 & 17 \\
\hline Ankle & 3 & 5 & 19 & 21 & 28 & 10 & 86 \\
\hline Foot & 1 & 2 & 4 & 3 & 5 & 1 & 16 \\
\hline Others & 1 & 3 & 6 & 5 & 2 & 4 & 21 \\
\hline Number of injuries & 12 & 54 & 52 & 57 & 56 & 47 & 278 \\
\hline
\end{tabular}

Table 3. Number of club player injuries related to level of activity

\begin{tabular}{|c|c|c|c|c|c|c|}
\hline \multirow[b]{2}{*}{ Location } & \multicolumn{5}{|c|}{ Level of club players } & \multirow[b]{2}{*}{$n$} \\
\hline & $\begin{array}{l}\text { Elite and } \\
\text { divisional }\end{array}$ & Series & $\begin{array}{c}\text { Non- } \\
\text { Competitive }\end{array}$ & Youth & Unknown & \\
\hline Arm/shoulder & 2 & 1 & 2 & 2 & & 7 \\
\hline Hands/fingers & 7 & 18 & 13 & 3 & 4 & 45 \\
\hline Knee & 4 & 5 & 4 & & & 13 \\
\hline Ankle + foot & 21 & 20 & 9 & 3 & 10 & 63 \\
\hline Others & 4 & 4 & 1 & 1 & 4 & 14 \\
\hline Number of injuries & 38 & 48 & 29 & 9 & 18 & 142 \\
\hline
\end{tabular}

Note: 139 club players incurred 142 injuries.

Table 4. The trauma mechanism of injury

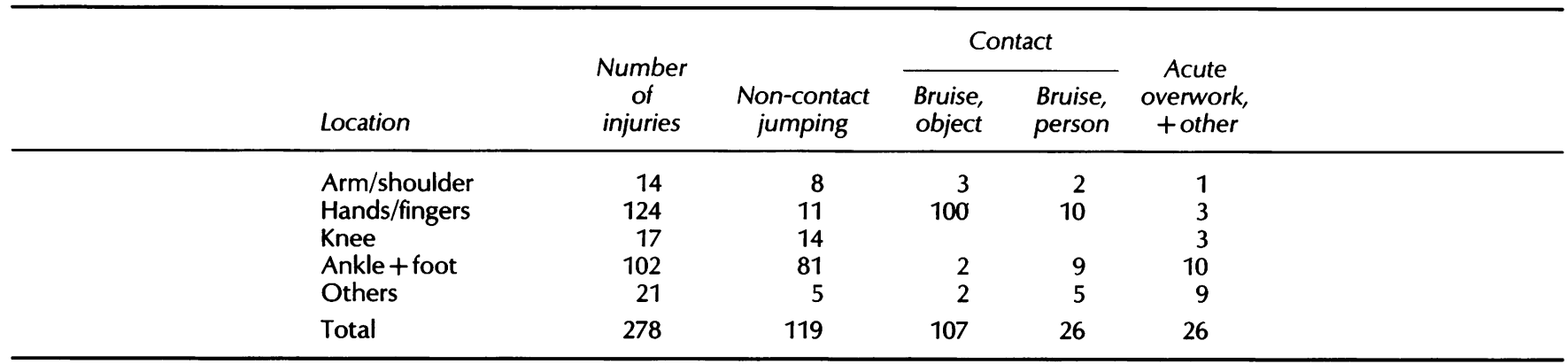

injuries (79\%) were non-contact injuries (Table 4). One hundred of the hand and finger injuries $(81 \%)$ occurred during contact with the ball in the overhand pass position, and only $11(9 \%)$ while blocking or spiking. The high level club players incurred non-contact injuries during jumping, while players active during leisure time and youth players were generally injured by contact with the ball, mostly during overhand passing.

\section{Post-traumatic care of the injury}

Four injuries (all of the knee) resulted in admission for inpatient care. Twenty percent of the injuries, mostly of the ankle, needed further outpatient care.

Sixty three percent of the injured players had treatment outside the hospital during the period of rehabilitation. Forty one percent used supportive devices and $31 \%$ used taping (more than one choice possible). Five percent of the players recieved treatment from a physiotherapist.

In general, $12 \%$ of the players did not have a satisfactory period of rehabilitation, while in $26 \%$ the rehabilitation was partly satisfactory. Patients with knee and ankle injuries were the most dissatisfied. 'Faulty instructions from the physician' $(23 \%)$, or 'own lack of consideration' $(22 \%)$ were the most frequent subjective causes of a less successful rehabilitation.

During rehabilitation, knee injuries received the most serious attention by both the trainers and players, while fractures of the hands or fingers and shoulder/arm injuries were taken least seriously.

\section{Consequences of the injury}

Eighty eight of the injuries (39\%) resulted in sick leave, and 26 suffered economic loss from their injury (12\%).

Twenty nine percent of the non-competitive players were absent for more than three months from practice or games.

The severity of the injuries was also expressed in absence from practice or games, and in the time needed to reach the previous activity level (Table 5): $44 \%$ of the injuries resulted in an absence of more than one month; $40 \%$ the knee injured players were absent from sport for more than three months. A large number of players with ankle $(36 \%)$ and finger ( $15 \%)$ injuries reached their 
Table 5. Duration of absence and time of regaining previous activity level after injury at follow up

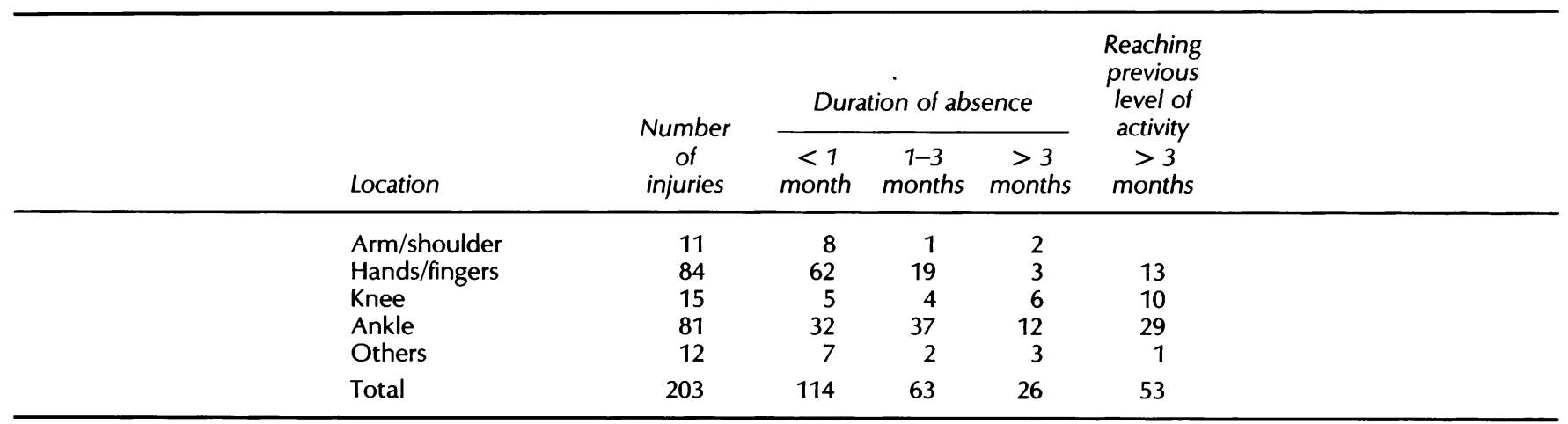

Note: 10 players ( $n=213$ players at follow up) did not reply to this question.

previous activity level more than three months after returning to their sport.

\section{Discussion}

In a Danish casualty report including 1017 injured athletes, ${ }^{8}$ volleyball injuries were the third most common cause of all recorded sports injuries. Another study of 571 injured athletes in 17 different sports ${ }^{1}$ found that of all sports volleyball was the seventh most likely to cause injury. We found that volleyball ranked fourth as a source of injury. The injury rate among injured club players was higher than found by Schmidt-Olsen and Jørgensen or by Yde and Nielsen ${ }^{45}$ and similar to the figures of Backx et al. ${ }^{9}$

One drawback of the casualty study is that it gives a reduced view of the different types of sports injuries. It shows only the acute traumatic injuries, which have been reported before, ${ }^{8}$ and this study confirms the findings. Several investigations have shown a higher incidence of chronic knee injuries, ${ }^{10-12}$ but only one of the knee injured players in our study had a chronic overwork injury. Schafle $e^{2} \mathrm{al}^{6}$ considered that $21 \%$ of volleyball injuries were chronic with an acute exacerbation.

Prospective investigations of handball and soccer injuries have shown that knee injuries account for $9 \%$ and $19 \%$ of acute and chronic injuries injuries in club players. ${ }^{23}$ In this casualty study, knee injuries accounted for only $6 \%$ of the injuries, while the incidence of both acute and chronic knee injury among injured club players has been stated to be higher. ${ }^{45}$

Yde and Nielsen found that female players had mostly finger injuries, and the male players suffered ankle injuries. ${ }^{4}$ In our study, these characteristic differencies between female and male players were also found.

In the report from Schmidt-Olsen and Jørgensen, knee and shoulder injuries resulted in the longest absence from the sport. ${ }^{5}$ In our study, showing more acute traumatic injuries, a relatively short duration of absence from sports was observed in the majority of the patients.

Evaluation of rehabilitation periods and treatment showed a degree of dissatisfaction. This was possibly due to the fact that in Danish hospitals inexperienced doctors staff casualty wards, and therefore some of the complaints might be justified.

Most of the injuries in our study occurred at lower level clubs, unlike those of Yde and Nielsen, who found that most sports injuries occurred in competition. ${ }^{4}$ This might indicate that some higher level injured players seek medical treatment outside casualty wards.

The many oveahnd pass finger injuries among female players, and among lower level club players, could indicate a need for training these groups technically to prevent such injuries.

Schafle $e t a l^{6}$ found that playing at the net was approximately three times more hazardous than playing in the back row. They also found that $48 \%$ of the players with ankle sprains reported contact with opponents or team mates as the cause of injury.

Our study showed that the majority of the ankle injuries occurrd during jumping at the net, mostly as non-contact injuries. This indicates that two or three man blocking techniques should be intensively practised to prevent such injuries. Referees should also watch carefully for foot faults at the net, to protect the players from landing at the feet of their team members or opponents and thus causing distortion of the ankle. This may indicate the need to change the international rules of the game; at the present time a player is allowed to step under the net at the midline, as long as this does not disturb the opposing players.

\section{Acknowledgements}

We wish to thank Elizabeth and Lesley Mayers and Physiotherapist Steven Kadin for language editing.

\section{References}

1 de Loës M, Goldie I. Incidence rate of injuries during sport activity and physical exercise in rural Swedish municipality: incidence rates in 17 sports. Int J Sports Med 1988; 9 : 461-7.

2 Jørgensen U. The epidemiology of injuries in typical Scandinavian sports. Br J Sports Med 1984; 18 : 59-67.

3 Nielsen AB, Yde J. Epidemiology and traumatology of injuries in soccer. Am J Sports Med 1989; 17: 803-8.

4 Yde J, Nielsen AB. Epidemiological and traumatological analysis of injuries in a Danish volleyball club. Ugeskr Lager 1988; 150: 1022-3. 


\section{Volleyball injuries: L Solgård et al.}

5 Schmidt-Olsen S, Jørgensen U. The pattern of injuries in Danish elite volleyball. Ugeskr Laeger 1987; 149 : 473-4.

6 Schafle MD, Requa RK, Patton WL, Garrick JG. Injuries in the 1987 National Amateur Volleyball Tournament. Am J Sports Med 1990; 18 : 624-31.

7 Greene TA, Hillmann SK. Comparison of support provided by a semirigid orthosis and adhesive ankle taping before, during, and after exercise. Am J Sports Med 1990; 18: 498-506.

8 Lang-Jensen T. Acute sports Injuries. I. A one-year material from a casualty department. Ugeskr Laeger 1982; 144: 3603-17.
9 Backx FJ, Beijer HJM, Bol E, Erich WB. Injuries in high-risk persons and high-risk sports. Am J Sports Med 1991; 19: 124-30.

10 Ferretti A, Ippolito E, Mariani P, et al. Jumper's knee. Am J Sports Med 1983; 11: 58-62.

11 Ferretti A, Puddu G, Mariani P, et al. Jumper's knee. An epidemiological study of volleyball players. Physician Sportsmed 1984; 12: 97-106.

12 Kujala UM, Aalto T, Österman K, Dahlström S. The effect of volleyball playing on the knee extensor mechanism. Am J Sports Med 1989; 17: 766-9. 